\title{
Dabigatran and myocardial infarction: a foggy scenario
}

\author{
This article was published in the following Dove Press journal: \\ Vascular Health and Risk Management \\ 20 January 2014 \\ Number of times this article has been viewed
}

\section{Daniele Pontillo' \\ Nicolino Patruno ${ }^{2}$ \\ 'Division of Cardiology, Hospital Complex Belcolle, Pavilion Montefiascone Montefiascone, Italy; ${ }^{2}$ Division of Cardiology, San Giuseppe Hospital, Albano Laziale (RM), Italy}

\section{Dear editor}

The pooled analysis from Clemens et $\mathrm{al}^{1}$ furnishes an up-to-date contribution on the scenario of the risk of myocardial infarction (MI) of patients on dabigatran in any disease setting, formulating a "non-guilty" sentence in favor of dabigatran in terms of net clinical benefit, even though the authors did find an absolute increase in MIs. We believe that this contribution may represent further evidence favoring the overall efficacy of dabigatran, in agreement with data from Hohnloser et $\mathrm{al}^{2}$ who analyzed the cardiovascular (CV) ischemic outcomes from the RE-LY (Randomized Evaluation of Long-term anticoagulant therapy) study and finding no statistically significant difference of MI between dabigatran and the comparison treatment, and with those from Dans et $\mathrm{al}^{3}$ who considered solely CV mortality with no further discrimination. Essentially, this represents the leitmotif of the last three years after the revised adjudication of cardiovascular events in the RE-LY study ${ }^{4}$ with a non-significant increase in MIs with dabigatran at any dose (for $150 \mathrm{mg}$ twice a day, relative risk 1.27, $0.94-1.71, P=0.12$ ).

However, a recent meta-analysis from Artang et $\mathrm{al}^{5}$ supports the hypothesis that direct thrombin inhibitors as a class may induce more MIs, and that this may not be solely attributed to lack of protective effect of warfarin. The pathophysiologic concept that warfarin may handle more effectively the thrombin burst in acute coronary syndromes with respect to direct thrombin inhibitors ${ }^{6}$ is very appealing and is highlighted by the results from Lip and Lane, ${ }^{7}$ furnishing sufficient explanation for the meta-analytical results against MI. ${ }^{8,9}$

On these grounds, we think it could be useful to share some considerations to gain an in-depth understanding of a complex and undefined phenomenon in the absence of specific randomized trials addressing MI. Firstly, the pre-specified criteria of MI were erratically declared in the studies included in any meta-analysis, thus representing a confounding factor in terms of homogeneity and ultimately in the identification of $\mathrm{CV}$ outcomes. Moreover, there is no doubt that ST elevation and non-ST elevation MI are two distinct pathophysiological entities, whereas the latter may be frequently not related to coronary atherosclerosis. Unfortunately, this issue was not specified in randomized trials involving direct thrombin inhibitors.

Another pitfall may be attributed to lack of evaluation of the concomitant preexisting antiplatelet medication throughout the studies, with potential confounding effects on $\mathrm{CV}$ outcomes. To our knowledge there are no published data regarding
Division of Cardiology, Hospital Complex

Belcolle, Pavilion Montefiascone

Montefiascone (VT), 01027, Italy

Email daniele.pontillo@gmail.com submit your manuscript | www.dovepress.com

Dovepress

http://dx.doi.org// 0.2/47/VHRM.S57529
Vascular Health and Risk Management 20I4:10 45-48

cc (i) (5) 2014 Pontillo and Patruno. This work is published by Dove Medical Press Limited, and licensed under Creative Commons Attribution - Non Commercial (unported, v3.0) License. The full terms of the License are available at http://creativecommons.org/licenses/by-n/3.0/. Non-commercial uses of the work are permitted without any further Press limited, provided the work is properly attributed. Permissions beyond the scope of the License are administered by Dove Medical Press Limited. Information on how to request permission may be found at: http://www.dovepress.com/permissions.php 
this issue (with the exception of bleeding events), and this may be the reason for which the authors did not consider concomitant antiplatelet therapy as a variable in the analysis. In a similar fashion, Artang et $\mathrm{al}^{5}$ did not take into consideration co-medication with aspirin and/or clopidogrel on outcomes. Nonetheless, it would be interesting to evaluate the potential protective effect of antiplatelet therapy together with dabigatran.

In this unclear scenario we are of the opinion that craving prospective data instead of additional confusing and contradictory meta-analyses may lead to more convincing and sound results for everyday clinical practice. Recently the FDA has proposed a study that will use data from the FDA Mini-Sentinel Distributed Database (MSDD) including nearly 100 million patients to assess systematically the rates of bleeding and thromboembolic outcomes associated with the use of dabigatran and warfarin for patients with atrial fibrillation, and that will furnish additional information regarding MIs (http://mini-sentinel.org/assessments/ medical events/details.aspx?ID=219).

\section{Disclosure}

The authors report no conflicts of interest in this correspondence.

\section{References}

1. Clemens A, Fraessdorf M, Friedman J. Cardiovascular outcomes during treatment with dabigatran: comprehensive analysis of individual subject data by treatment. Vasc Health Risk Manag. 2013;9: 599-615.

2. Hohnloser SH, Oldgren J, Yang S, et al. Myocardial ischemic events in patients with atrial fibrillation treated with dabigatran or warfarin in the RE-LY (randomized evaluation of long-term anticoagulation therapy) trial. Circulation. 2012;125(5):669-676.

3. Dans AL, Connolly SJ, Wallentin L, et al. Concomitant use of antiplatelet therapy with dabigatran or warfarin in the randomized evaluation of long-term anticoagulation therapy (RE-LY) trial. Circulation. 2013;127(5): 634-640.

4. Connolly SJ, Ezekowitz MD, Yusuf S, Reilly PA, Wallentin L. Randomized evaluation of long-term anticoagulation therapy investigators. Newly identified events in the RE-LY trial. N Engl J Med. 2010;363(19):1875-1876.

5. Artang R, Rome E, Nielsen JD, Vidaillet HJ. Meta-Analysis of Randomized Controlled Trials on Risk of Myocardial Infarction from the Use of Oral Direct Thrombin Inhibitors. Am J Cardiol. 2013;112(12):1973-1979. Epub September 25, 2013.

6. Dale B, Eikelboom JW, Weitz JI, et al. Dabigatran attenuates thrombin generation to a lesser extent than warfarin: could this explain their differential effects on intracranial hemorrhage and myocardial infarction? J Thromb Thrombolysis. 2013;35(2):295-301.

7. Lip GYH, Lane DA. Does warfarin for stroke thromboprophylaxis protect against MI in atrial fibrillation patients? Am J Med. 2010;123(9): 785-789.

8. Uchino K, Hernandez AV. Dabigatran association with higher risk of acute coronary events: meta-analysis of noninferiority randomized controlled trials. Arch Intern Med. 2012;172(5):397-402.

9. Mak KH. Coronary and mortality risk of novel oral antithrombotic agents: a meta-analysis of large randomised trials. BMJ Open. 2012;2(5): e001592. 


\section{Authors' reply}

\section{Andreas Clemens' \\ Mandy Fraessdorf ${ }^{2}$ \\ Jeffrey Friedman ${ }^{3}$}

'Corporate Division Medicine, TA Cardiovascular, ${ }^{2}$ Medical Data Services, Boehringer Ingelheim GmbH \& Co KG, Ingelheim am Rhein, Germany; ${ }^{3}$ Boehringer Ingelheim Pharmaceuticals Inc, Ridgefield, CT, USA

Correspondence: Andreas Clemens

Boehringer Ingelheim Pharma GmbH \& Co KG,

Bingerstrasse 173, 55216 Ingelheim am Rhein, Germany

Tel +4961327790606

Fax +4961327290606

Email andreas.clemens@boehringer-ingelheim.com

\section{Dear editor}

We appreciate the comments and agree with the discussion points raised by Pontillo and Patruno on the challenges of the numerous recent meta-analysis regarding myocardial infarction (MI) in patients with atrial fibrillation (AF). As mentioned by Pontillo and Patruno, the intent of our metaanalysis was to further understand MI aspects in studies with dabigatran etexilate in a broader evaluation of studies, higher number of patients, and by using individual patient data in contrast to previous analyses by others. We agree that the conclusions made by Hohnloser et $\mathrm{al}^{1}$ and also Dans et $\mathrm{al}^{2}$ are the most rigorous and highest quality prospective evaluation of the aspects around MI. Our analysis supports their conclusion that the overall favorable risk-benefit profile of dabigatran in the prevention of cardiovascular outcomes in patients with AF, with or without concomitant antiplatelet treatment, is favorable to warfarin. This conclusion is further supported by a number of preclinical data showing a favorable effect of dabigatran on progression of coronary artery disease (CAD) eg, plaque stability and growth. ${ }^{3}$

As mentioned by Pontillo and Patruno, meta-analyses are less stringent when compared to prospectively conducted clinical trials regarding true observed effects. However, there is a major difference between our meta-analysis and others. Most meta-analyses pool dabigatran data across different dosages, different indications and comparators, and different patient populations with a variable set of risk factors, not taking into account the influence which these differences may have on the MI profile of the drug. We tried to address some of these limitations by eg, grouping the results with the same comparators and by using patient level data. With this we believe that the results of our analysis seem to be of the best achievable quality in the field of meta-analyses. So overall the conclusion on the available clinical and also pre-clinical evidence can be drawn that MI is not an adverse drug reaction of the direct thrombin inhibitor (DTI), dabigatran.

The hypothesis by Dale et al, ${ }^{4}$ the lack of inhibition of the "thrombin burst" by a DTI versus a factor Xa inhibitor is based on an assay performed in a test tube under static conditions, without endothelium or vessel wall and is probably a large oversimplification of a clinical scenario. It may or may not have clinical relevance. Interestingly when looking into higher risk patients (eg, patients with acute coronary syndrome $[\mathrm{ACS}]$ ) no significant reduction of the individual outcome of MI by the factor Xa inhibitor rivaroxaban was shown in the ATLAS ACS 2-TIMI 51 (Anti-Xa Therapy to Lower Cardiovascular Events in Addition to Standard Therapy in Subjects with Acute Coronary Syndrome ACS2-Thrombolysis In Myocardial Infarction 51) trial. ${ }^{5}$ Furthermore, no dose response was seen in this trial. Only the composite of cardiovascular endpoints, as in RE-LY (Randomized Evaluation of Long-term anticoagulant therapY), allowed for significant results - but as in contrast to RE-LY, this was a comparison versus placebo. Quite confusing is the aspect that rivaroxaban was used in a twice daily dosing with a four times lower dosing compared to the once daily dose used in patients with AF. For apixaban versus placebo no MI reduction was evident in ACS patients either and the benefit risk ratio did not support for such an indication. ${ }^{6}$ On the other hand the DTI bivalirudin shows clear benefit in this patient population ${ }^{7}$ but mainly due to a better bleeding profile. The injectable factor Xa inhibitor otamixaban failed to show benefits in this setting mainly driven by a worse safety profile in terms of bleeding. ${ }^{8}$

We therefore finally agree with Pontillo and Patruno that only well designed prospective evaluations of the new oral anticoagulants (NOACs) will clarify these somewhat confusing findings around $\mathrm{MI}$ - also especially when compared to active controls like well-controlled warfarin. Therefore, the results of the new studies which look into this aspect specifically, are eagerly awaited: the RE-DUAL PCI trial ${ }^{9}$ comparing dabigatran etexilate versus warfarin in patients undergoing PCI with stent implantation in AF patients; this trial announced recently at the American Heart Association congress, ${ }^{9}$ and an investigator initiated trial, the Management of Myocardial Injury After Noncardiac Surgery Trial (MANAGE trial), ${ }^{10}$ which evaluates dabigatran in a placebo environment. We are looking forward to the results of these prospective randomized trials to provide further data on dabigatran etexilate in patients at risk of recurrent MI. 


\section{Disclosure}

Andreas Clemens, Mandy Fraessdorf, and Jeffrey Friedman are full time employees of Boehringer Ingelheim.

\section{References}

1. Hohnloser SH, Oldgren J, Yang S, et al. Myocardial ischemic events in patients with atrial fibrillation treated with dabigatran or warfarin in the RE-LY (Randomized Evaluation of Long-Term Anticoagulation Therapy) trial. Circulation. 2012;125(5):669-676. Epub January 3, 2012.

2. Dans AL, Connolly SJ, Wallentin L, et al. Concomitant use of antiplatelet therapy with dabigatran or warfarin in the Randomized Evaluation of Long-Term Anticoagulation Therapy (RE-LY) trial. Circulation. 2013;127(5):634-640. Epub December 27, 2012.

3. Borissoff JI, Otten JJ, Heeneman S, et al. Genetic and pharmacological modifications of thrombin formation in apolipoprotein e-deficient mice determine atherosclerosis severity and atherothrombosis onset in a neutrophil-dependent manner. PLoS One. 2013;8(2):e55784.

4. Dale B, Eikelboom JW, Weitz JI, et al. Dabigatran attenuates thrombin generation to a lesser extent than warfarin: could this explain their differential effects on intracranial hemorrhage and myocardial infarction? J Thromb Thrombolysis. 2013;35(2):295-301.
5. Gibson CM, Chakrabarti AK, Mega J, et al. Reduction of stent thrombosis in patients with acute coronary syndromes treated with rivaroxaban in ATLAS-ACS 2 TIMI 51. J Am Coll Cardiol. 2013;62(4): 286-290.

6. Alexander JH, Lopes RD, James S, et al. Apixaban with antiplatelet therapy after acute coronary syndrome. $N$ Engl J Med. 2011;365(8): 699-708.

7. Ten Y, Devlin G. Bivalirudin in acute coronary syndromes and percutaneous coronary intervention: should we use it? Heart Lung Circ. 2013;22(10):793-800.

8. Steg PG, Mehta SR, Pollack CV Jr, et al. Anticoagulation with otamixaban and ischemic events in non-ST-segment elevation acute coronary syndromes: the TAO randomized clinical trial. JAMA. 2013;310(11): 1145-1155.

9. Boehringer Ingelheim. Boehringer Ingelheim planning two new Global Clinical Trials for Pradaxa ${ }^{\circledR}$ (dabigatran etexilate) in expanded patient populations [press release]. Ingelheim am Rhein: Boehringer Ingelheim; November 19, 2013. Available from: http:/www.boehringer-ingelheim. com/news/news_releases/press_releases/2013/19_november_2013_ dabigatranetexilate1.html. Accessed December 04, 2013.

10. Population Health Research Institute. Management of Myocardial Injury After Noncardiac Surgery Trial (MANAGE). Available from: http:// clinicaltrials.gov/show/NCT01661101. NLM identifier: NCT01661101. Accessed December 5, 2013.
Vascular Health and Risk Management

\section{Publish your work in this journal}

Vascular Health and Risk Management is an international, peerreviewed journal of therapeutics and risk management, focusing on concise rapid reporting of clinical studies on the processes involved in the maintenance of vascular health; the monitoring, prevention and treatment of vascular disease and its sequelae; and the involvement of

\section{Dovepress}

metabolic disorders, particularly diabetes. This journal is indexed on PubMed Central and MedLine. The manuscript management system is completely online and includes a very quick and fair peer-review system, which is all easy to use. Visit http://www.dovepress.com/ testimonials.php to read real quotes from published authors. 